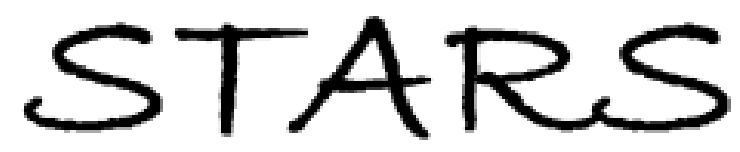

University of Central Florida

STARS

Faculty Bibliography 1990s

Faculty Bibliography

$1-1-1998$

\title{
The deadweight loss of christmas: Comment
}

Bradley J. Ruffle

Orit Tykocinski

Find similar works at: https://stars.library.ucf.edu/facultybib1990

University of Central Florida Libraries http://library.ucf.edu

This Article is brought to you for free and open access by the Faculty Bibliography at STARS. It has been accepted for inclusion in Faculty Bibliography 1990s by an authorized administrator of STARS. For more information, please contactSTARS@ucf.edu.

\section{Recommended Citation}

Ruffle, Bradley J. and Tykocinski, Orit, "The deadweight loss of christmas: Comment" (1998). Faculty Bibliography 1990s. 2335.

https://stars.library.ucf.edu/facultybib1990/2335

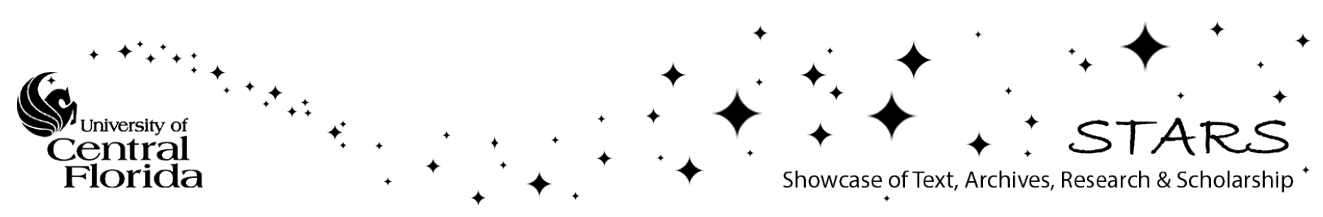




\title{
The Deadweight Loss of Christmas: Comment
}

\author{
By Bradley J. Ruffle AND ORIT TyKocinSKI*
}

Two previous surveys used to measure the welfare implications of Christmas gift-giving in the United States have reached opposite conclusions. Joel Waldfogel (1993) finds a welfare reduction of 13 percent or more associated with Christmas giving. Curiously, Sara J. Solnick and David Hemenway's (1996) (henceforth, $\mathrm{SH})$ replication of Waldfogel's survey turns up just the opposite result: a 214-percent welfare gain. We design a series of controlled laboratory experiments to determine why the two papers arrive at opposite conclusions. We do not produce our own estimate of the deadweight loss of gift-giving; rather, our aim is to understand how, and which among, the differences in methodology between the two studies account for their divergent findings.

Waldfogel (1993) surveyed 58 students enrolled in an intermediate microeconomics class about specific gifts they had received for Christmas. He asked recipients to estimate the amount paid by the giver for each gift received. Recipients were then asked to place a value on each gift they received. Respondents were instructed to estimate the value of a gift as the "....amount of cash such that you are indifferent between the gift and the cash, not counting the sentimental value of the gift" (p. 1331). Waldfogel measures the welfare yield of a gift as the difference between the recipient's valuation and her cost estimate of the gift. Based on 278 gifts reported, Waldfogel finds that gifts have an average yield of 87.1 percent, indicating that gifts lose about 13 percent of their value in the exchange from giver to receiver. When cash gifts are excluded, the average yield falls further to 83.9 percent.

\footnotetext{
* Ruffle: Department of Economics, Ben Gurion University, P.O.B. 653, Beer Sheva, 84105, Israel (e-mail: bradley@bgumail.bgu.ac.il); Tykocinski: Department of Behavioral Sciences, Ben Gurion University, Beer Sheva, 84105, Israel (e-mail: oritt@bgumail.bgu.ac.il). We thank Tomer Bakalash for research assistance and Sara Solnick, Todd Kaplan, three anonymous referees of this journal, and seminar participants at Ben Gurion University, Universite Louis Pasteur, and the 1998 ESA meetings in Mannheim for comments.
}

SH were intrigued enough by Waldfogel's results to replicate his study. Contrary to Waldfogel, SH find that gift-giving is actually welfare improving with an average yield of 214 percent (median yield 111 percent). They claim that a broader subject pool than that questioned by Waldfogel explains the reversal. Concerned that undergraduates in an intermediate microeconomics class may be unrepresentative, $\mathrm{SH}$ administered their survey to members of the general public at train stations and airports and to staff and graduate students enrolled in a biostatistics or an economics class at the Harvard School of Public Health. They also altered the question used to elicit respondents' valuations of gifts received. Their survey question reads as follows (p. 1300): "Aside from any sentimental value, if, without the giver ever knowing, you could receive an amount of money instead of the gift, what is the minimum amount of money that would make you equally happy?" The change in wording from "the amount of cash such that you are indifferent" to the "amount of money that would make you equally happy" was prompted by a concern that "indifference" is a technical word familiar only to economists. It remains to be seen whether SH's "equally happy" question is substantially equivalent to the "indifference" version of the question or whether they have introduced a greater change than they realize.

An additional methodological concern is that the cost estimates always precede respondents' valuations in both studies. Order effects are well documented in the social psychology literature: ${ }^{1}$ cost estimates may influence valuations. In particular, costs may serve as a judgmental anchor upon which to base value estimates. Reversing the order of the questions is a technique common to survey and experimental methods in the social sciences to balance the researcher's design and offset possible order effects.

\footnotetext{
${ }^{1}$ Howard Schuman and Stanley Presser (1981) provide a good starting point in this literature.
} 


\section{Experimental Design}

We design a series of seven distinct, controlled experiments (treatments) that permit us to examine the above-stated conjectures. In each treatment, subjects are presented with one object, followed by a second one. The subject is asked to "imagine that [she] received the object as a gift from someone." She subsequently indicates either her valuation of the gift $(V)$, or her cost estimate of the gift $(C)$, or both. In order to compare Waldfogel's study with that of $\mathrm{SH}$, the value question appeared either in the indifference version $\left(V_{i}\right)$ or the equally happy version $\left(V_{h}\right)$. Following Waldfogel and $\mathrm{SH}$, the three questions were written as follows: ${ }^{2}$

$\left(V_{i}\right)$ "Aside from any sentimental value of the gift, indicate an amount in shekels which would cause you to be indifferent between receiving the gift and receiving the cash."

$\left(V_{h}\right)$ "Aside from any sentimental value of the gift, if, without the giver ever knowing, you could receive an amount of money instead of the gift, what is the minimum amount of money that would make you equally happy? Indicate an amount in shekels."

(C) "In your opinion, how much money did the giver pay for the gift? Indicate an amount in shekels."

Allowing for reversal of the order in which the value and cost questions appear, the seven treatments can be summarized as: $V_{i} C, C V_{i}$, $V_{h} C, C V_{h}, V_{i}, V_{h}$, and $C$.

Each subject remained in the same treatment for both objects, that is, answered the same question or pair of questions for both objects. For the two objects we chose a practical one and a decorative one. We sought objects that would have a broad appeal and which were not gender biased. One object was an attractive table lamp

\footnotetext{
${ }^{2}$ The actual questionnaires administered to subjects were translated to Hebrew. In an effort to ensure that the meaning and undercurrents of the original surveys remained intact, we employed the double-translation method in which one person translates from the original to Hebrew and another, unfamiliar with the original, from Hebrew to English. We used both economists and noneconomists for this task. Like its English equivalent, the Hebrew word for "indifferent," "adeesh," has several dictionary meanings, the two most important of which for the purposes of this study are: "showing no preference" and "unconcerned or having no interest or feeling."
}

with a gold base and a glass, emerald-green shade in the shape of a half cylinder (retail price: 159 shekels, $=\$ 45$ USD at the time the experiments were conducted). The other object was a brown, hand-carved, African wooden mask of dimensions 1 meter $\times 50 \mathrm{~cm}$, purchased in Israel (retail price: 800 shekels, = $\$ 227$ USD). The order in which the objects were presented was balanced across subjects so that roughly half saw the lamp first, and the other half saw the mask first. ${ }^{3}$

The usefulness of these experiments is that they allow us to discern whether the form of the value question matters by comparing $V_{i}$ with $V_{h}$. We can also test for order effects by comparing $V_{i} C$ with $C V_{i}$ and $V_{h} C$ with $C V_{h}$, and whether estimates alone $\left(V_{i}, V_{h}, C\right)$ differ from those when paired with another question (treatments $\left.V_{i} C, C V_{i}, V_{h} C, C V_{h}\right)$.

It is worth emphasizing that we are not interested in the welfare gain or loss of any individual treatment. ${ }^{4}$ All of our hypotheses involve value or cost comparisons across treatments.

Finally, we come to SH's claim that a more representative subject pool accounts for their reversal of Waldfogel's deadweight loss finding. This is easily testable within the framework of our design. We recruited an approximately equal number of economists and noneconomists and divided both groups between all seven treatments and the two object orderings in roughly equal fractions.

Our sample consists of 414 subjects. 240 subjects were undergraduate students enrolled in psychology classes majoring in either behavioral sciences or human resources (henceforth referred to as psychologists for the sake of brevity). The remaining 174 students were undergraduate economics majors at Ben Gurion University. For comparability with Waldfogel's

\footnotetext{
${ }^{3}$ Note that the element of Christmas is absent from our experimental design. While there may indeed be something unique concerning the welfare of gift-giving at Christmas compared to other holidays and occasions, the more significant distinction is between modern gift-giving which serves a primarily social function and gift-giving in primitive societies in which gifts served as a prelude to trade, a form of insurance and a form of lending.

${ }^{4}$ Given the fact that the lamp and the mask are "imposed gifts," not chosen with the recipient in mind (and not actually given), we expect estimated costs to exceed substantially valuations.
} 
TABLE 1-REgRESSION REsults

\begin{tabular}{|c|c|c|c|c|c|c|c|c|c|c|c|c|c|}
\hline $\begin{array}{l}\text { Dependent } \\
\text { variable }\end{array}$ & Constant & Female & Psych & $\begin{array}{l}\text { Lamp } \\
\text { first }\end{array}$ & $\begin{array}{l}\text { Value } \\
\text { alone }\end{array}$ & $\begin{array}{l}\text { Cost } \\
\text { alone }\end{array}$ & $\begin{array}{l}\text { Cost } \\
\text { first }\end{array}$ & $V_{h}$ & $\log \left(V_{\text {pair }}\right)$ & $\log \left(C_{\text {pair }}\right)$ & $\bar{R}^{2}$ & $N$ & $\begin{array}{l}\text { N.B. outliers } \\
\text { excluded }\end{array}$ \\
\hline $\begin{array}{l}\text { Lamp Value } \\
\quad(L V)\end{array}$ & $\begin{array}{c}111.62 \\
(0.008)\end{array}$ & $\begin{array}{r}6.79 \\
(0.606)\end{array}$ & $\begin{array}{r}7.58 \\
(0.570)\end{array}$ & $\begin{array}{r}22.58 \\
(0.079)\end{array}$ & $\begin{array}{r}19.64 \\
(0.134)\end{array}$ & & & $\begin{array}{r}59.31 \\
(0.000)\end{array}$ & & & 0.068 & 345 & 8 \\
\hline $\log \left(L V_{\text {pair }}\right)$ & $\begin{array}{r}0.038 \\
(0.856)\end{array}$ & $\begin{array}{r}0.068 \\
(0.155)\end{array}$ & $\begin{array}{r}0.016 \\
(0.744)\end{array}$ & $\begin{array}{r}0.014 \\
(0.765)\end{array}$ & & & $\begin{array}{r}0.006 \\
(0.893)\end{array}$ & $\begin{array}{r}0.197 \\
(0.000)\end{array}$ & & $\begin{array}{r}0.834 \\
(0.000)\end{array}$ & 0.382 & 230 & 5 \\
\hline $\begin{array}{l}\text { Mask Value } \\
\qquad(M V)\end{array}$ & $\begin{array}{l}176.41 \\
(0.193)\end{array}$ & $\begin{array}{r}51.04 \\
(0.235)\end{array}$ & $\begin{array}{r}40.66 \\
(0.352)\end{array}$ & $\begin{array}{r}32.99 \\
(0.435)\end{array}$ & $\begin{array}{r}42.10 \\
(0.326)\end{array}$ & & & $\begin{array}{l}119.75 \\
(0.003)\end{array}$ & & & 0.024 & 346 & 7 \\
\hline $\log \left(M V_{\text {pair }}\right)$ & $\begin{array}{r}0.020 \\
(0.918)\end{array}$ & $\begin{array}{r}0.045 \\
(0.352)\end{array}$ & $\begin{array}{r}0.089 \\
(0.083)\end{array}$ & $\begin{array}{r}0.003 \\
(0.952)\end{array}$ & & & $\begin{array}{r}0.066 \\
(0.150)\end{array}$ & $\begin{array}{r}0.154 \\
(0.001)\end{array}$ & & $\begin{array}{r}0.912 \\
(0.000)\end{array}$ & 0.486 & 228 & 7 \\
\hline $\begin{array}{l}\text { Lamp Cost } \\
\quad(L C)\end{array}$ & $\begin{array}{r}94.33 \\
(0.013)\end{array}$ & $\begin{array}{r}10.25 \\
(0.414)\end{array}$ & $\begin{array}{r}38.32 \\
(0.003)\end{array}$ & $\begin{array}{r}7.62 \\
(0.543)\end{array}$ & & $\begin{array}{r}22.72 \\
(0.123)\end{array}$ & & & & & 0.026 & 288 & 8 \\
\hline $\log \left(L C_{\text {pair }}\right)$ & $\begin{array}{r}1.46 \\
(0.000)\end{array}$ & $\begin{array}{r}0.017 \\
(0.621)\end{array}$ & $\begin{array}{r}0.084 \\
(0.016)\end{array}$ & $\begin{array}{r}0.025 \\
(0.446)\end{array}$ & & & $\begin{array}{r}0.014 \\
(0.661)\end{array}$ & $\begin{array}{r}0.076 \\
(0.021)\end{array}$ & $\begin{array}{r}.379 \\
(.000)\end{array}$ & & 0.320 & 231 & 4 \\
\hline $\begin{array}{l}\text { Mask Cost } \\
\quad(M C)\end{array}$ & $\begin{array}{r}46.59 \\
(0.789)\end{array}$ & $\begin{array}{r}40.11 \\
(0.485)\end{array}$ & $\begin{array}{l}232.52 \\
(0.000)\end{array}$ & $\begin{array}{r}1.69 \\
(0.976)\end{array}$ & & $\begin{array}{r}89.27 \\
(0.191)\end{array}$ & & & & & 0.050 & 290 & 6 \\
\hline $\log \left(M C_{\text {pair }}\right)$ & $\begin{array}{r}1.23 \\
(0.000)\end{array}$ & $\begin{array}{l}0.015 \\
(0.663)\end{array}$ & $\begin{array}{l}0.150 \\
(0.000)\end{array}$ & $\begin{array}{r}0.002 \\
(0.960)\end{array}$ & & & $\begin{array}{r}0.021 \\
(0.530)\end{array}$ & $\begin{array}{r}0.034 \\
(0.318)\end{array}$ & $\begin{array}{r}.485 \\
(.000)\end{array}$ & & 0.496 & 228 & 7 \\
\hline
\end{tabular}

Notes: Estimated OLS regression coefficients with $p$-values in parentheses. The dependent variables lamp and mask value ( $L V$ and $M V$ ), lamp and mask cost $(L C$ and $M C$ ) are expressed as a function of subject gender, major, object presentation order, and treatment dummies (whether the value or cost question was paired or asked alone and, in the case of pairing, whether the cost question appeared first or second, and the version of the value question asked). The first regression in each pair uses the data from all seven treatments. In the second regression of each pair, observations from those three treatments in which the value or cost question appeared alone are dropped. Thus, the logged versions of the within-subject estimates of value and cost from those treatments in which these questions appear together are used.

study, we chose economics students currently enrolled in intermediate microeconomics classes or in an economic history class for which intermediate micro is a prerequisite.

\section{Findings}

Table 1 reports the results of OLS regressions. ${ }^{5}$ For each dependent variable, lamp value $(L V)$, mask value $(M V)$, lamp cost $(L C)$, and mask cost $(M C)$, there are a pair of regressions. The first regression in each of the four pairs uses all the data and thus permits us to estimate the

\footnotetext{
${ }^{5}$ To deal with the problem of outliers, we eliminate observations whose studentized residual is three or more standard deviations away from the mean. For each observation, a regression is estimated based on all other $N-1$ observations. The difference between the predicted dependent variable and its actual value is the predicted residual. Dividing by its standard error yields the studentized residual. (See David Belsley et al. [1980] for a detailed explanation of this outlier procedure.)
}

influence of asking value and cost questions alone versus pairing them. The dummy variable "Value alone" ("Cost alone") equals one for treatments in which the value (cost) question is asked alone, and zero when paired. The second regression in each pair appears in double-log specification. ${ }^{6}$ It focuses on those treatments in which the cost and value questions are paired (treatments $V_{i} C, C V_{i}, V_{h} C, C V_{h}$ ). Thus, for value estimates $(L V, M V)$, we exclude treatments $V_{i}$ and $V_{h}$. For cost estimates we exclude the lone treatment in which cost appears alone (treatment $C$ ). In this way, we are able to measure the impact of the ordering of the value and cost questions on subjects' estimates. The treatment variable "Cost first" assumes a value of zero when value appears before cost (treatments

\footnotetext{
${ }^{6}$ The double-log specification describes the relationship between Value and Cost better than linearity in these variables. The coefficients on the log-independent variables can be interpreted as elasticities.
} 
$V_{i} C$ and $V_{h} C$ ), and a value of one when the reverse holds (treatments $C V_{i}$ and $C V_{h}$ ).

The treatment dummy $V_{h}$ assumes a " 0 " value for treatments in which the indifference version of the value question was asked and a " 1 " value when the equally happy version was used. The coefficients of this variable in all four of the value regressions point decisively to the paper's main result.

OBSERVATION 1: Valuations given in response to the equally happy question are much higher than those given in the indifference version, whereas cost estimates are invariant to the version of the value question with which they are paired. Taken together, these findings indicate that the welfare yield from the equally happy treatments is markedly higher than that from the indifference treatments.

The mean valuation for the lamp given for the equally happy formulation was 165 shekels, median $=150$, more than 50 percent higher than valuations elicited from the indifference version, mean 105, median $=100$. Similarly, the mask elicited a mean valuation of 445 shekels, median $=300$, in the equally happy treatments compared to a mean of only 324 , median $=200$, in the indifference treatments. $t$-tests of means and the regression coefficients (Table 1) indicate that all of these differences are significant beyond the 0.1percent level.

The dummy variable "psych" takes on a " 0 " value for economists and a "1" for psychologists and brings us the second result.

OBSERVATION 2: There is no significant difference between the valuations of economists and psychologists. On the other hand, psychologists give higher cost estimates than economists indicating that gifts to economists provide a higher welfare yield than gifts to psychologists.

Psychologists and economists gave identical value estimates for the lamp, mean values of 135 shekels. For the mask, psychologists' mean valuation was 402 compared to a mean valuation of 360 by economists. Both the "psych" coefficient for the $M V$ regression ( $p$-value = $0.35)$ and a $t$-test of means $(p$-value $=0.30)$ reveal that this difference is not significant. ${ }^{7}$ Psychologists' cost estimates, on the other hand, were substantially higher than those of economists for both the lamp and the mask. According to Waldfogel's measure of welfare, this implies that gifts to economists actually have a higher welfare yield than those to psychologists, contrary to SH's claim. ${ }^{8}$ The psychologists indicated cost estimates for the lamp 35 shekels or 24 percent greater than those obtained from the economists ( $p$-value $=0.01$ in $t$-test). The magnitude of this finding increases for the mask: psychologists gave average cost estimates of 603 shekels compared to economists' average of 375 shekels. The difference of 228 shekels or 61 percent is significant beyond the 0.1-percent level.

OBSERVATION 3: Whether cost or value estimates are elicited first does not affect the estimates themselves. However, value estimates alone are weakly greater than when paired with cost estimates; and cost estimates alone are weakly less than when paired with value estimates.

This last point should not be overstated as the results are not strongly significant ( $p$-values from the four "Value alone" and "Cost alone" regression coefficients range from 0.12 to 0.33 ). Nonetheless, they do suggest that welfare estimates may increase when estimates of value and cost are temporally separated. Asking about cost and value together may undermine value by

\footnotetext{
${ }^{7}$ The reversal in the sign of the regression coefficient for "psych" from $L V$ to $L V_{\text {pair }}$ and from $M V$ to $M V_{\text {pair }}$ reflects a tendency among psychologists only to indicate higher valuations when the value question appears alone (psychologists' mean values for value alone treatments are 164 and 429 for the lamp and mask, respectively) than when it is paired with the cost question (psychologists' mean valuations for such paired treatments are 131 and 380 for the lamp and mask, respectively). An interaction dummy variable composed of "psych" and "Value alone", and a $t$-test of means for the mask show this tendency is not statistically significant. A $t$-test of means for the lamp, however, rejects the equality of means at the 6-percent level.

${ }^{8}$ Of course, Waldfogel uses recipients' cost estimates in his definition of welfare because he cannot obtain actual costs. When available, value estimates minus actual costs form the more natural measure of welfare yield. This is not to exclude the possibility that the recipient's perception of a gift's cost may influence her valuation of the gift.
} 
changing the judgmental frame of reference from a holistic assessment that includes nonmaterial aspects to a colder, more calculating, materially bound assessment. As footnote 7 suggests, different subject pools may be more or less susceptible to this effect.

With one exception, the order in which the lamp and the mask were presented to subjects does not affect their value and cost estimates: lamp value estimates appear sensitive to the order of presentation. The coefficient of 22.58 on "Lamp first" ( $p$-value $=0.08)$ indicates that lamp value estimates increase when the lamp is shown after the more expensive mask. Higher value estimates on the mask provide an anchor or point of reference from which subsequent lamp value judgments are made.

\section{Discussion}

Is gift-giving a source of deadweight loss? Our results indicate that it depends critically on how you ask the question and, to a lesser degree, on whom you ask. ${ }^{9}$ That economists offer lower cost estimates and therefore have a greater welfare yield for gifts than psychologists contradicts SH's claim. This finding suggests that an expensive gift given to signal wealth or intent may not be adequately appreciated by an economist.

However, the paper's most significant result is that the form of the value question dramatically affects the apparent welfare yield of gifts. That subtle changes in wording can drastically affect subject response has been established in a vast array of domains, including individual choice problems and preference reversals, experimental bargaining games, and the valuation of public goods using contingent valuation survey methods. Particularly in written surveys, in which written words are the only inputs available to respondents (as opposed to face-to-face or telephone surveys in which visual or oral prompts may be used), wording takes on a disproportionate importance.

\footnotetext{
${ }^{9}$ Our results support John A. List and Jason F. Shogren's (1998) intuition that "sample selection may not be the pivotal issue in this debate." They produce their own estimate of the welfare yield of gifts using a random $n$th price auction in which subjects indicate the prices at which they are willing to sell individual gifts received for Christmas.
}

"Equally happy" probably puts respondents in a more cheerful or optimistic frame of mind compared to the cold, sterile term "indifferent." The word "happy" may prime or automatically activate a set of positive emotions which are subsequently applied to the gift value assessments. This priming of emotions occurs unbeknownst to the respondent and in spite of explicit instructions to exclude emotions. ${ }^{10} \mathrm{On}$ the other hand, our experiments support SH's critique that "indifferent" is a technical term natural to economists but unfamiliar to noneconomists. Among the 99 psychology students who responded to the indifference version of the value question, 10 raised their hands to ask about the meaning of the word.

\section{Concluding Remarks}

While this paper ostensibly concerns the welfare implications of gift-giving, it more directly addresses survey and experimental methodology. Two methodological points are in order. First, Vernon L. Smith (1994) lists seven reasons to conduct an experiment. The experiments reported in this paper establish an eighth reason: to evaluate the content and robustness of one or more field studies. Just as the experimental laboratory can be used to discriminate between competing theories (number one on Smith's list), the crucial elements of conflicting field studies may be brought under the control of the experimenter to determine what underlies the results. ${ }^{11}$

Second, our results suggest that individuals do not always carry around with them readily accessible, preformulated valuations of objects. Instead these assessments are often first formulated upon request and thereby sensitive to a number of methodological considerations including context, the precise wording of respondents' instructions and the order and timing of events. This is particularly true in environments in which considerations other than strategy, such as emotions and fairness, may influence

\footnotetext{
${ }^{10}$ See John Bargh (1988) for a further discussion of the cognitive process underlying the unconscious priming of emotions.

${ }^{11}$ Some of these issues are considered in the unpublished version of this comment which is available for download at Ruffle's website: http://econ.bgu.ac.il/faculty/bradley.
} 
behavior. Future efforts into the welfare implications of gift-giving should therefore bear in mind these methodological issues in designing their data collection methods. Other issues not closely examined herein include the type of gift given, the validity of excluding sentimental value, and the representativeness of the respondents, particularly along the dimensions of culture and age. Finally, although hypothetical gifts may provide greater experimental control, one should be aware of the possible differences between real and hypothetical gifts when estimating the welfare yield of gifts.

\section{REFERENCES}

Bargh, John. "Automatic Information Processing: Implications for Communication and Affect," in L. Donohew, H. Sypher, and T. Higgins, eds., Communication, social cognition, and affect. Hillsdale, NJ: Erlbaum, 1988, pp. 9-32.
Belsley, David; Kuh, Edwin and Welsch, Roy. Regression diagnostics: Identifying influential data and sources of collinearity. New York: Wiley, 1980.

List, John A. and Shogren, Jason F. "The Deadweight Loss of Christmas: Comment." American Economic Review, December 1998, 88(5), pp. 1350-55.

Schuman, Howard and Presser, Stanley. Questions and answers in attitude surveys: Experiments on question form, wording and context. New York: Academic Press, 1981.

-Smith, Vernon L. "Economics in the Laboratory." Journal of Economic Perspectives, Winter 1994, 8(1), pp. 113-31.

Solnick, Sara J. and Hemenway, David. "The Deadweight Loss of Christmas: Comment." American Economic Review, December 1996, 86(5), pp. 1299-305.

Waldfogel, Joel. "The Deadweight Loss of Christmas." American Economic Review, December 1993, 83(5), pp. 1328-36. 


\section{This article has been cited by:}

1. Christie A. Klimas, Benjamin Shaffer. 2019. Exploring the impact of holiday gifts: An economic and environmental comparison of DVDs and books received as gifts. Sustainable Production and Consumption 19, 11-24. [Crossref]

2. Marc Bourreau, Pınar Doğan. 2018. Gains from digitization: Evidence from gift-giving in music. Journal of Economic Behavior \& Organization 149, 106-122. [Crossref]

3. Pinar Dogan, Marc Bourreau. 2018. Gains from Digitization: Evidence from Gift-Giving in Music. SSRN Electronic Journal . [Crossref]

4. Geoffrey Propheter. Markets, Efficiency, and Governance 38-52. [Crossref]

5. Laura Birg, Anna Goeddeke. 2014. Christmas Economics - A Sleigh Ride. SSRN Electronic Journal . [Crossref]

6. William Easterly, Claudia R. Williamson. 2012. Rhetoric versus Reality: The Best and Worst of Aid Agency Practices. SSRN Electronic Journal . [Crossref]

7. Niloufar Ghoreishi, Mark J Jakiela, Ali Nekouzadeh. 2011. A cost model for optimizing the take back phase of used product recovery. Journal of Remanufacturing 1:1. . [Crossref]

8. Oz Shy. 2011. A Short Survey of Network Economics. Review of Industrial Organization 38:2, 119-149. [Crossref]

9. Hans Olav Melberg. 2010. Conceptual Problems with Studies of the Social Cost of Alcohol and Drug Use. Nordic Studies on Alcohol and Drugs 27:4, 287-304. [Crossref]

10. Oz Shy. 2010. A Short Survey of Network Economics. SSRN Electronic Journal . [Crossref]

11. Thomas K Bauer, Christoph M Schmidt. 2009. Haben und nicht haben - Eine Analyse der Wertschätzung von Weihnachtsgeschenken in Deutschland. Schmollers Jabrbuch 129:4, 523-538. [Crossref]

12. Todd R. Kaplan, Bradley J. Ruffle. 2009. In search of welfare-improving gifts. European Economic Review 53:4, 445-460. [Crossref]

13. Kristine E. Principe, Joseph G. Eisenhauer. 2009. Gift-giving and deadweight loss. The Journal of Socio-Economics 38:2, 215-220. [Crossref]

14. Erik Schokkaert. Chapter 2 The Empirical Analysis of Transfer Motives 127-181. [Crossref]

15. Joel Waldfogel. 2005. Does Consumer Irrationality Trump Consumer Sovereignty?. Review of Economics and Statistics 87:4, 691-696. [Crossref]

16. Lucy F. Ackert, Bryan K. Church, Gerald P. Dwyer. 2005. When the Shoe is on the Other Foot: Experimental Evidence on Evaluation Disparities. SSRN Electronic Journal . [Crossref]

17. Todd R. Kaplan, Bradley J. Ruffle. 2004. The Self-serving Bias and Beliefs about Rationality. Economic Inquiry 42:2, 237-246. [Crossref]

18. Joel Waldfogel. 2003. Does Consumer Irrationality Trump Consumer Sovereignty? Evidence from Gifts and Own Purchases. SSRN Electronic Journal . [Crossref]

19. Joel Waldfogel. 2002. Gifts, Cash, and Stigma. Economic Inquiry 40:3, 415-427. [Crossref]

20. Todd R. Kaplan, Bradley J. Ruffle. 2001. The Self-Serving Bias and Beliefs about Rationality. SSRN Electronic Journal . [Crossref]

21. Bradley J. Ruffle, Todd R. Kaplan. 2001. Here's Something You Never Asked For, Didn't Know Existed, and Can't Easily Obtain: A Search Model of Gift Giving. SSRN Electronic Journal . [Crossref]

22. Joel Waldfogel. 2001. Gifts, Cash, and Stigma. SSRN Electronic Journal . [Crossref] 
23. Sara J. Solnick,, David Hemenway. 2000. The Deadweight Loss of Christmas: Reply. American Economic Review 90:1, 325-325. [Citation] [View PDF article] [PDF with links] 